
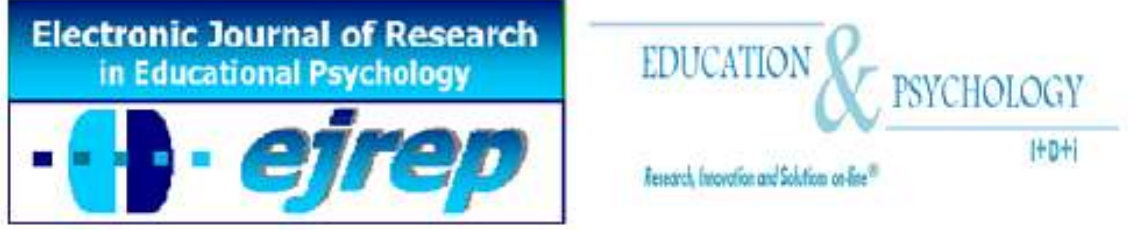

\title{
The interface of creativity, fluency, lateral thinking, and technology while designing Serious Educational Games in a science classroom
}

\section{Richard Lamb ${ }^{1}$, Leonard Annetta ${ }^{2}$ \& David Vallett ${ }^{3}$}

\author{
${ }^{1}$ Department of Teaching and Learning, Washington State University \\ ${ }^{2}$ College of Education and Human Development, George Mason University \\ ${ }^{3}$ Department of Teaching and Learning, University of Nevada Las Vegas
}

\section{United States of America}

Correspondence: Richard Lamb. Washington State University; 327 Cleveland Hall; Pullman, WA 99164. United States of America. E-mail: richard.lamb@wsu.edu

(C) Education \& Psychology I+D+i and Ilustre Colegio Oficial de la Psicología de Andalucía Oriental (Spain) 


\section{Abstract}

Introduction. Creativity is the production of the new, original, unique, and divergent products and ideas mediated through lateral thinking. Evidence suggests that high levels of creativity and fluency are important in the continued development of student interest, efficacy and ultimately career impact in the sciences.

Method. In this study, 559 randomly selected students attended an eight-month long workshop on science-based videogame design as a learning tool in the classroom. Students then designed science-based video games exemplifying learned, key, science concepts. Upon completion of the workshop, all students were given the Torrance Test of Creative Thinking to aid in the development of understanding of the relationship between creativity and related constructs.

Results. The authors also explore the implications of the role of lateral thinking as a cognitive system mediating science learning. Results suggest a statistically significant difference exists between pretest and posttest outcomes and that the data confirms the suggested model for the role of creative, fluency and lateral thinking related to science processing.

Discussion and Conclusion. Seeking to promote interest in creative support tools such as those in use during the design of SEGs can provide disciplinary convergence through lateral thinking. More specifically these result agree with results found in other studies such as Yamamoto \& Nakakoji (2005), Chen et.al. (2007) and Spencer, Lucas \& Claxton (2012), which suggest that there are underlying behavioral manifestations of creativity and fluency that impacts the science and design process via lateral thinking.

Keywords: Lateral Thinking; Cognition; Science Education; Educational Nueropsychology 


\section{La interrelación de la creatividad, fluidez, pensamiento lateral y tecnología a la hora de diseñar Juegos Educativos Serios en un aula de ciencias naturales}

\section{Resumen}

Introducción. La creatividad es la producción de los nuevos, originales, únicos, y divergentes productos e ideas mediadas a través del pensamiento lateral. La evidencia sugiere que los altos niveles de creatividad y la fluidez son importantes en el desarrollo continuo de interés de los estudiantes, la eficacia y en última instancia, el impacto de carrera en las ciencias.

Método. En este estudio, 559 estudiantes seleccionados al azar asistieron a un taller largo de ocho meses, para el diseño de videojuegos basados en la ciencia como herramienta de aprendizaje en el aula. Posteriormente, los estudiantes diseñan videojuegos basados en la ciencia que ejemplifican aprendidas, conceptos clave de la ciencia. Al finalizar el taller, todos los estudiantes se les dió la prueba de Pensamiento Creativo de Torrance para ayudar en el desarrollo de la comprensión de la relación entre la creatividad y las construcciones relacionadas.

Resultados. Los autores también explorar las implicaciones de la función del pensamiento lateral como un sistema cognitiva media en el aprendizaje de las ciencias. Los resultados sugieren que existe una diferencia estadísticamente significativa entre el pre-test y post-test y los resultados que los datos confirman el modelo sugerido por el papel de la creatividad, la fluidez y el pensamiento lateral en relación con el procesamiento de la ciencia.

Discusión y conclusión. Tratando de promover el interés en las herramientas de apoyo creativas tales como los que se utilizan durante el diseño de SEGs puede proporcionar convergencia disciplinaria a través del pensamiento lateral. Más específicamente estos resultados están de acuerdo con los resultados encontrados en otros estudios como Ya-mamoto y Nakakoji (2005), Chen et al (2007) y Spencer, Lucas \& Claxton (2012), que sugieren que hay manifestaciones conductuales subyacentes de la creatividad y la fluidez que afecta el proceso de la ciencia y el diseño a través de pensamiento lateral.

Palabras clave: Pensamiento lateral, cognición, enseñanza de la ciencia, neuropsicología educativa. 


\section{Introduction}

Students within the United States struggle to maintain adequate position within the contexts of international testing and competitions in both mathematics and science (Chow, 2012). In addition, there is considerable pressure to promote creativity and fluency as a means to develop the next generation of technological and scientific innovations within government agencies and companies. For example, the National Science Foundation, Intel, Microsoft, and Google all engage in competitive funding awards specifically identifying creativity as a goal. Other organizations also routinely offer contests promoting large awards for innovation and creative applications of science (Adams, Turns \& Atman, 2003; Wilson, Vyakarnam, Volkmann, Mariotti \& Rabuzzi, 2009). However, more recently awards for large national grants have fallen to less than $5 \%$ of proposals submitted. In this context of increased competition many educators and researchers are at a loss to explain how these important traits (creativity and fluency) integrate with science as part of the science classroom and as a whole (Anwar, Rasool \& Haq, 2012). It is of note that an important facet of the Nature of Science is the inclusion of creativity as a beneficial mechanism in science endeavors (Haigh, 2013, McComas, 2012; Urhahne, Kremer, \& Mayer, 2011; Holliday \& Lederman, 2013).

The purpose of this paper is to outline the role of creativity and fluency in science and the science classroom as a function of the cognitive processing system associated with lateral thinking. Consideration of the seriousness of the need to understand creativity and its related constructs thusly demands further research by the science education community into the relationships and functions of this complex construct. Research on creativity, its role in science, and the use of creativity support tools in the classroom are in its infancy (Shneiderman et.al. 2008). In this paper, several operational definitions are used; the first creativity support tools are the tools that aid in the development of creativity associated cognitive systems and related constructs (Myers, Hudson \& Pausch, 2000). The authors of the study define creativity as the production of the new, original, unique and divergent products, and ideas mediated through the cognitive system known as lateral thinking (Andreasen \& Ramchandran, 2012; Crutchfield, 1962; Gotz, 1981; Thorstuon, 1952; Torrance, 1970). The authors of the study define fluency as the number and flexibility of the ideas and approaches used to accomplish a task or solve a problem as mediated through lateral thinking (Almeida, Prieto, Ferrando, Oliveria \& Ferrandiz, 2008; Resnick, Berg \& Eisenberg, 2000; Torrance, 1970). Lateral thinking is a 
cognitive system responsible for the integration of disparate outputs from preceding cognitive attributes and the inputs from the environment. Evidence suggests that high levels of creativity and fluency are important in the continued development of student interest, efficacy, and ultimately impact career selection (Ray \& Smith, 2010). Thus, in order to make use of creativity and fluency, one must first know their relationship to other constructs and provide for their measurement.

\section{Theoretical Framework}

The development of the proposed model suggested in this paper arises out of the connectionist biological framework. Within this this framework, the mind is a product of the brain arising from the interconnection of neurons in the form of cognitive systems. As the individual moves through and interacts with their environment, continuous data streams are processed by cognitive systems. The functional processing component of the cognitive system is the cognitive attribute. Some examples of cognitive attributes include lateral thinking, critical reasoning, retrieval, and parity judgment. Within these interactions, the modularity of the mind and brain allows these systems known as cognitive attributes to engage in information processing using selected data channels (Zylberberg, Slezak, Roelfsema, Dehaene, \& Sigman, 2010; Lamb, 2013; Lamb, 2014; Lamb \& Annetta, 2012; Lamb \& Annetta, 2009). It is in this processing of information that the innate releasing mechanisms trigger quantifies component parts of fixed behaviors when suitable antecedent stimulations are present (Arciniegas, 2013). Within human cognition, thought, behavior, and affect arise from the complex structured sequences and fragments assembling to achieve goals, such as completing a task in a science classroom (Duncan, 2013).

\section{Review of the Literature}

Recent research in cognitive neuropsychology has identified and traced distinct neural systems involved in higher brain functions used for the generation of new ideas and problem solving strategies (Vartanian, Bristol, \& Kaufman, 2013; Atkins, \& Adolphs, 2011). Current conceptualization of these cognitive systems arises as a hierarchical framework with multiple cognitive attributes acting as data processing systems (Lamb, 2013). Two examples of these systems are the disintegrative system of critical thinking (Halpern, 1998; Goodchild \& Janelle, 2010) and the integrative system of lateral thinking (Deininger, Loudon, \& Norman, 2012; Tseng \& Lin, 2012). Lamb, Annetta, Vallett, \& Sadler (2014) have developed a computational model examining these cognitive systems using artificial neural networks (ANNs) to 
simulate systemic interactions between the attributes. The current computational model of student cognition using ANNs is the Student Task and Cognition Model (STAC-M) (Lamb, Vallett, Akmal, \& Baldwin, 2014). The importance of these systemic interactions is evident in the number of species within the animal kingdom using complex cognitive systems to interact and manipulate their environments (Boysen \& Capaldi, 2014; Camazine, 2003). Due to the large numbers of species making use of integrative and disintegrative cognitive systems it follows that evolutionary pressures place great emphasis on the development and integration of these multiple cognitive systems as a means to survive. One particular integrative neural system is that of creativity, lateral thinking, and fluency (Benedek, Jauk, Fink, Koschutnig, Reishofer, Ebner, \& Neubauer, 2014).

\section{Creativity}

A growing interest in creativity and other affective measures has accompanied the rise of the alternative-assessment measurement movement in the STEM domain (Lamb, Annetta, Meldrum, \& Vallett, 2011; Lamb, \& Annetta, 2012, Lamb, Vallett, \& Annetta, 2014). This development arises out concerns from the endpoints of the STEM pipeline and other stakeholders (business and government) that students are not developing the ability to make the intuitive leaps often associated with creativity (Kaufman, Plucker \& Russell, 2012). The ability to measure and effect creativity in relation to science will allow educators to target interventions that assist in the development and understanding of the role of this important construct. Creativity in the form of lateral thinking is a foundational aspect of human information processing. Creativity, involves two defining characteristics; the first is the ability to develop novel works or processes and the second is that the work is adaptive within the task constraints as divergent functions (Amabile, 1983; Sawyer, 2011). While there is literature within the education field linking creativity to student outcomes there is little discussing the underlying cognitive systems and processing occurring during student science-task completion. In other words, there seems to be some consensus that creativity is important to science but educators and researchers are not sure of the linkage between science information processing and the underlying cognitive systems associated with creativity. One proposed linkage between science processing and creativity is through the cognitive architecture associated with lateral thinking (Ellamil, Dobson, Beeman, \& Christoff, 2012). 


\section{Lateral Thinking}

At this point, it becomes important to address the difference between creativity and lateral thinking. Within this study, the authors identify creativity as the product based (behavioral) output of a cognitive system in this case the cognitive system of lateral thinking. The counterpoint to lateral thinking as an integrative system is that of critical reasoning as a disintegrative system. Educators define critical reasoning or logical reasoning as the formation of conclusions, inferences, or judgments based upon stimulus input (Simmons, 2010). Science educators suggest that critical reasoning is a key or even the key attribute used in the science learning process (Bond, Philo, \& Shipton, 2011). However, this narrow view of student cognition ignores the nonlinear dynamic systems associated with student science learning. Taken as a system critical reasoning alone does not sufficiently explain student processing of science information in the classroom. Critical reasoning as a cognitive system is a disintegrative information parsing cognitive attribute (Baillargeon, $\mathrm{Li}$, Gertner, \& Wu, 2011). Within this cognitive system, an integrative data processing attribute is required to complete the information processing and ultimately make sense of the input from the environment (Crowder, Carbone, \& Friess, 2014). Researchers using imaging studies have identified lateral thinking as this integrative cognitive system. This cognitive system centers in the ventromedial and dorsolateral aspects of the prefrontal subcortex (Roy, Chohamy, \& Wagner, 2012). These portions of the brain provide the infrastructure to integrate disparate (parsed by critical thinking) data streams by providing a buffer to hold information within the mind and order the data streams in place and time (Dietrich, 2003). The integrative aspect of lateral thinking manifests itself behaviorally as creativity (Christoff, Gordon, Smith, \& Vancouver, 2011). Studies examining subjects that have sustained ventromedial prefrontal cortex damage show there is a deficit in the ability to integrate multiple data streams and are unable to provide novel and adaptive responses to tasks and situations (Kurzban, Duckworth, Kable, \& Myers, 2013). In other words, they lack creativity. Integration of multiple data streams provides a means to explain individual differences identified in creative thought. These individual differences arise from the recruitment of multiple cognitive attributes as a system to integrate multiple data streams (Gramann, Gwin, Ferris, Oie, Jung, Lin, \& Makeig, 2011). Neuroscience data strongly supports the notion that the prefrontal cortex is the structural component acting to pull and superimpose relevant information from long-term storage and environmental stimulus and move it to the working memory buffer then to prefrontal sub cortex for processing (Morcom, Bullmon, Huppert, Lennox, Praseedom, Linnington, \& Fletcher, 2010). It is the superimposition of one form of information on another that is the integrative effect (Brockner 
\& Wiesenfeld, 1996). It is at this point that it becomes possible for the insertion of previous science content knowledge among other forms of knowledge to solve science-based tasks again seen behaviorally as creativity.

\section{General Fluency}

Fluency within the Torrance Test of Creativity is a measure of the number of attempts the subject makes in an attempt to produce an outcome (Onarheim \& Friis-Olivarius, 2013). Within this view fluency is a sufficient condition for the manifestation of creativity (Meyer \& Lederman, 2013). Understanding the interrelationship of sufficient and necessary logic, there is considerable debate in education as to the role and importance of fluency in the Torrance Test of Creative Thinking (Surkova, 2012). Researchers have been unable to reconcile the role of fluency within the construct of creativity. This in part seems due to the treatment of fluency in connection to creativity as behavioral outcome and not lateral thinking as a cognitive process. Examination of this seemingly irreconcilable aspect of the Torrance creativity framework one could posit that that the field of education reexamines the idea of fluency from a different perspective. Within this novel (neuropsychological) framework, fluency could be examined as the number of superimpositions and combinations that the individual is able to make when processing data streams within the lateral thinking cognitive architecture (Barres, Simmons, \& Arbib, 2013). Theses superimpositions occur at an approximate average rate of 89 impositions per second with many of superimpositions occurring subconsciously as the data stream interacts with the cognitive attributes and systems (Myers, 1995). Outwardly or behaviorally, these key superimpositions manifest as an outward attempt the subject makes toward task completion. The more superimpositions and combinations of data streams the subject uses the more likely the output will be novel and develop the "creative" jumps seen within novel approaches in science. Given the latent nature of the data stream processing it becomes difficult within the Torrance framework to ascertain the difference between multiple superimpositions of data suggesting the Torrance Test does not fully account for the significant aspects of creativity.

\section{Rationale}

With the renewed emphasis on creativity as an aspect of the Nature of Science.The inclusion of such goals in national curricular standards including the Next Generation Science Standards and the Common Core standards on mathematical modeling, a study of potential means to foster creativity and fluency in the STEM classroom is needed (Achieve, Inc., 2013; Com- 
mon Core Standards Initiative, 2014). This is particularly apparent given the aforementioned corporate emphasis on innovation (Adams, Turns \& Atman, 2003; Wilson, Vyakarnam, Volkmann, Mariotti \& Rabuzzi, 2009)

\section{Purpose, Research Questions, and Hypothesis}

The purpose of this study is to establish the relationship between creativity, general fluency, and lateral thinking in relation to science information processing. A secondary purpose of this paper is to lay foundational work for the inclusion of lateral thinking as an integrative cognitive attribute. The research questions and associated hypothesis addressed within this study are:

Research Question 1 (RQ1): What is the relationship between creativity, general fluency, and lateral thinking?

Research Question 2 (RQ2): What is the role of lateral thinking in relation to science learning?

Research Question 3 (RQ3): Does the use of science based SEGs improve creativity behaviors as exhibited on the Torrance Test of Creative Thinking?

Consideration of the research questions results in the following hypothesizes:

Hypothesis 1 (H1): using suitable data and theoretical framing, it is possible to establish a relationship between creativity, lateral thinking, and fluency.

Establishing the relationship between these constructs will allow for examination of the complex cognitive and behavioral processes seen within the science classroom.

Hypothesis $2(\mathrm{H} 2)$ : lateral thinking acts as the integrative cognitive attribute (system) allowing for the gains seen within science learning due to creativity.

The hypothesis that lateral thinking acts as an integrative cognitive attribute would support the current cognitive computational models STAC-M (Lamb, Vallett, Akmal, \& Baldwin, 2014). More importantly, conformation of this hypothesis would provide evidence for the data channel view of cognition and situate the cognitive attributes critical reasoning and lateral thinking as core data processing components of the cognitive systems related to science information processing. Substantiation of these hypotheses would suggest that lateral thinking is an important counterpoint to critical thinking and not just an interesting aspect of science information processing. Lateral thinking is a necessary component with important implications for educators in the science classroom. 


\section{Method}

\section{Participants}

The authors obtained data from 559 randomly selected high school students (grades 10-12) from two different high schools in the Mid-Atlantic and southeastern regions of the United States. Researchers collected data during workshops attended by the students over an eightmonth period. Workshop participants engaged in the development -through the Design Process- of Science based Serious Educational Games (SEG) (Author, 2008) using a personal computer platform. The intent of the intervention was to provide increased outcomes in affect, content knowledge, and cognitive targets through the design and development of the SEGs. Key cognitive targets identified in the project are visuospatial orientation, mental rotation, creativity (suggested as a proxy for lateral thinking) and other cognitive attributes identified by the authors through cognitive diagnostics as developed by Lamb et. al. (2014). A majority of the students (309) reported being minority ethnicity with the remainder of the study participants listing Caucasian as their ethnic identifier. Table 1 provides an overview of the demographic data.

Table 1. Demographic characteristics of study participants.

\begin{tabular}{lccccr}
\hline Characteristic & Group & Intervention & Comparison & Percentage & $\mathrm{N}$ \\
\hline Gender & Male & 160 & 140 & 53.8 & 300 \\
& Female & 143 & 116 & 46.2 & 259 \\
\hline Age & 14 & 2 & 3 & 1.0 & 5 \\
& 15 & 110 & 98 & 37.2 & 208 \\
& 16 & 118 & 147 & 47.4 & 265 \\
& 17 & 40 & 32 & 12.8 & 72 \\
& 18 & 2 & 7 & 1.3 & 9 \\
\hline Ethnicity & African American & 41 & 38 & 14.1 & 79 \\
& American Indian & 2 & 4 & 1.3 & 6 \\
& Asian & 21 & 22 & 7.7 & 43 \\
& White & 172 & 157 & 58.9 & 329 \\
& Hispanic & 37 & 21 & 10.3 & 58 \\
& Multi-racial & 27 & 17 & 7.7 & 44 \\
\hline Grade & 10 & 5 & 2 & 1.3 & 7 \\
& 11 & 89 & 54 & 25.6 & 143 \\
& 12 & 234 & 175 & 73.1 & 409 \\
\hline Total & & 303 & 256 & $100.0 \%$ & 559 \\
\hline
\end{tabular}




\section{Instrumentation}

The Torrance Test of Creative Thinking (TTCT) (original $\alpha=.76$ ) was developed in 1966 and re-normed multi-times in an effort to understand and measure the construct of creativity. Psychologists recognize two versions of the tests -the figural and the verbal- as the premier means to establish scores for creativity. This recognition is primarily due to the standardized nature of the test administration and scoring. The scoring of the test makes the test particularly useful for establishing creativity as a scaled, comparative, and normed measure. Results of the study of creativity by the author (Torrance, 1970) have identified the construct (creativity) as latent and multifaceted. The Torrance test consists of five norm-referenced subscales, Fluency (labeled specific fluency in this paper), Originality, Abstractness of Titles, Elaboration and Resistance to Premature Closure. Torrance (1974) has discouraged the use of composite scores for the TTCT as they are misleading and each subscale acts semi-independently not making it viable to analyze using IRT models such as Rasch (Lamb et. al., 2014).

\section{Student Content Measures}

The science content assessment consisted of 25 multiple-choice questions (Rasch Reliability $=.84$, Infit $=.97$, Outfit $=1.45)$ developed by the authors. The authors also examined validity of the content through alignment with the Next Generation Science Standards. The author specifically aligned the measure with the Performance Expectations around HS-ESS31 Construct an explanation based upon evidence for how the availability of natural resources , occurrence of natural hazards, and changes in climate have influenced human activity. Three expert raters with backgrounds in science education examined the instrument for alignment and suitability of the question to the construct. Calculation of the construct validity (and qualitative item fit) coefficient is achieved using the equation $\mathrm{d}=\mathrm{I}_{\mathrm{D}} / \sum_{I=1}^{n} I_{\mathrm{A}-\mathrm{D}}$. Analysis of agreement shows 23 items having a strong relevance to the content standard and 2 items exhibited mixed relevance (weak and strong) to the standard. This percentage corresponds to a construct validity coefficient of 0.92 . This level of construct relevance is adequate for a content measure as the accepted cutoff score of an affective measure is a construct validity coefficient of 0.80 . The remaining items show a mixed relevance (i.e. one reviewer rated the item as strongly relevant and one reviewer rated the same item as weakly relevant or both reviewers rated the item as weakly relevant). 


\section{Procedure and design}

Study respondents completed an eight-month workshop on science-based videogame design and development as a learning tool in the science classroom. The study design is a pretestposttest comparison design. At the onset of the workshop, each participant answered pretest questions using the Torrance Test of Creative Thinking (TTCT) and on a test of science content knowledge related to topics ultimately taught in the classroom. Over the span of eight months, the subjects designed science-based video games exemplifying key science concepts in alternative energy they had learned during the workshop and during their classroom instruction. Upon completion of the workshop all students took the posttest TTCT and test of content knowledge. The pretest-posttest measurement in these areas established changes in creativity, fluency, and science content knowledge resulting from the integration of concepts used during videogame design in the science classroom. All students worked individually to answer survey and test questions online and did not validate answers with each other. The total time between pretest and posttest administration was eight-months in an effort to mitigate carry-over effects. Table 2 provides an overview of the study design.

Table 2. Study Design.

\begin{tabular}{lcccr}
\hline $\begin{array}{l}\text { Treatment } \\
\text { Condition }\end{array}$ & Group Label & Pretest & Treatment & Posttest \\
\hline Experimental & $\mathrm{E}$ & $\mathrm{O}_{1}$ & $\mathrm{X}$ & $\mathrm{O}_{2}$ \\
Comparison & $\mathrm{C}$ & $\mathrm{O}_{1}$ & - & $\mathrm{O}_{2}$ \\
\hline
\end{tabular}

\section{Data Analysis}

The authors developed a Structural Equation Model (SEM) using Mplus to determine whether group and mean differences exist post intervention and the relationship between the construct of creativity, fluency, and science knowledge processing. Each of the analyses in combination not only provides evidence of the changes in the measured constructs due to the intervention but also establishes the role of each construct in relation to each other. This provides evidence for the role and place of lateral thinking system. A Multiple Indicator Multiple Cause Structural Equation Modeling (MIMIC SEM) approach was used for the development of a proposed model of the interaction between creativity, lateral thinking, science knowledge processing, and the intervention. A second-order MIMIC SEM is a general approach to multivariate data analysis in which the purpose is to study the complex, causal, relationships 
among unobserved variables. The primary advantages of SEM over traditional multiple regression are; (a) more flexibility in the assumptions, (b) the use of confirmatory factor analysis to reduce measurement error, (c) test of multiple dependent variables, (d) measures direct and indirect effects including error and (e) provides superior results with missing, time-series, autocorrected and non-normal data (Ruo, Baker, Thompson, Murray, Huber \& Sudano, 2008).

\section{Results}

Results of the study provide evidence for the presence of general latent factor identified as lateral thinking. In addition, the results also provide evidence that there is significant change in student science knowledge and creativity scores. A secondary outcome based upon the results of analysis of the structural equation model suggests the presence of general latent factor lateral thinking.

\section{Analysis of variance results}

The ANOVA F-test results demonstrate that the TTCT is invariant across the factors of grade, gender, age and ethnicity (Almeida, 2008). Examination of internal consistency and reliability of the TTCT for this sample is .85. This level of internal consistency and reliability is adequate. Table 3 illustrates mean comparisons results. Further examination Table 3 illustrates statistically significant differences on the main effects of intervention gain score, and grouping comparison versus intervention.

Table 3. Summary of Comparisons

\begin{tabular}{lllllll}
\hline Factor & Score Type & df & $\begin{array}{l}\text { F- } \\
\text { Ratio }\end{array}$ & $\begin{array}{l}\text { p- } \\
\text { value }\end{array}$ & $\begin{array}{l}\text { Effect } \\
\text { Size }\end{array}$ & $\begin{array}{l}\text { Effect Size } \\
\text { Interpretation }\end{array}$ \\
\hline Comparison (C) & Gain Score & 1,558 & 1.52 & .218 & None & NS \\
Intervention (I) & Gain Score & 1,558 & 6.14 & .014 & .210 & Moderate \\
Group (C vs. I) & Posttest Score & 1,558 & 5.41 & .020 & .197 & Moderate \\
Grade & Gain Score & 2,558 & 2.47 & .086 & None & NS \\
Gender & Gain Score & 1,558 & 1.78 & .183 & None & NS \\
Age & Gain Score & 4,558 & 2.10 & .079 & None & NS \\
Ethnicity & Gain Score & 5,558 & 1.47 & .204 & None & NS \\
\hline
\end{tabular}

\section{Multiple Indicators Multiple Causes Structural Equation Model Results}

Structural equation model analysis of the Torrance Test for Creative Thinking illustrates that the data has excellent model fit, $X^{2}(3)=1.70, p=0.064$, RMSEA $=0.001$ CI $90 \%=[0.001$, 
0.008], CFI = 0.97, TLI=0.91 (Hu \& Bentler, 1999; Steiger, 1990). The authors of the student calculated the measure reliability using the latent trait reliability method because this method does not have the limitations associated with Cronbach's alpha as used in the original validation study (Dimitrov, 2012). Measurement reliability is calculated at .85, this level of internal consistency is considered good for this measure (Raykov, 2004). The resulting model is overidentified suggesting there are other rival models which the researcher can examine. However, examination of rival models shown in Table 4 via log-likelihood, AIC and BIC suggests that the proposed model is the most parsimonious of the models.

Table 4. Model Comparisons

\begin{tabular}{llll}
\hline Estimate & $\begin{array}{l}\text { Model 1 (Pro- } \\
\text { posed) }\end{array}$ & $\begin{array}{l}\text { Model 2 (Ri- } \\
\text { val 1) }\end{array}$ & Model 3 (Rival 2) \\
\hline log-likelihood & -322.489 & -242.47 & -131.27 \\
AIC & 1.298 & .986 & .826 \\
BIC & -2449.90 & -2597.51 & -3211.01 \\
\hline
\end{tabular}

\section{Model}

Item Parceling. Item parcels differ from subscales or scale scores in that the entire set of item parcels reflect a single latent construct (Cattell, 1956). Item parcels are preferred in this analysis as indicators as they are often more reliable indicators and more normally distributed. Scores of the item parcels are also often more continuous in nature; in addition, they require a smaller sample and avoids the problem of less than three indicators per construct in the confirmatory component of the SEM. The use of item parceling also increase the resolution of second order constructs within a SEM (March, Morin, Parker, \& Kaur, 2013).The resulting confirmatory second order model establishes the presence of three latent traits, Creativity and General Fluency, significantly covarying $(\xi=.54)$ with each other and with the construct of Lateral Thinking ( $\left.\lambda_{\text {Creativity }}=.74, \lambda_{\text {General Fluency }}=.97\right)$. Significant factors contributing to the latent trait of creativity are originality $(\lambda=.60)$, elaboration $(\lambda=.81)$ and resistance to closure $(\lambda=.80)$. The latent trait of general fluency consists of the specific fluency factor $(\lambda=.61)$ and an abstraction factor $(\lambda=.51)$. The factors of originality and specific fluency significantly correlate $(\phi=.49)$. Test type acts as a significant exogenous variable on the latent endogenous variables creativity $(\Upsilon=.60)$ and fluency $(\Upsilon=.21)$. Additionally, the examination of the test type connecting to Science Knowledge Processing is statistically significant indicating differences between the pretest and posttest for knowledge processing within the intervention group. 
The authors did not include residual variance of error for the latent variable and items for clarity purposes. The residual variance of errors for each item and variable range from $\Theta=$ .20 to $\Theta=.35$. Tests for measurement and structural invariance across the model suggest that the measured items meet the assumptions of invariance of factor loadings. Figure 1 illustrates the confirmatory model of the relationship between creativity, lateral thing, science knowledge processing, and general fluency.

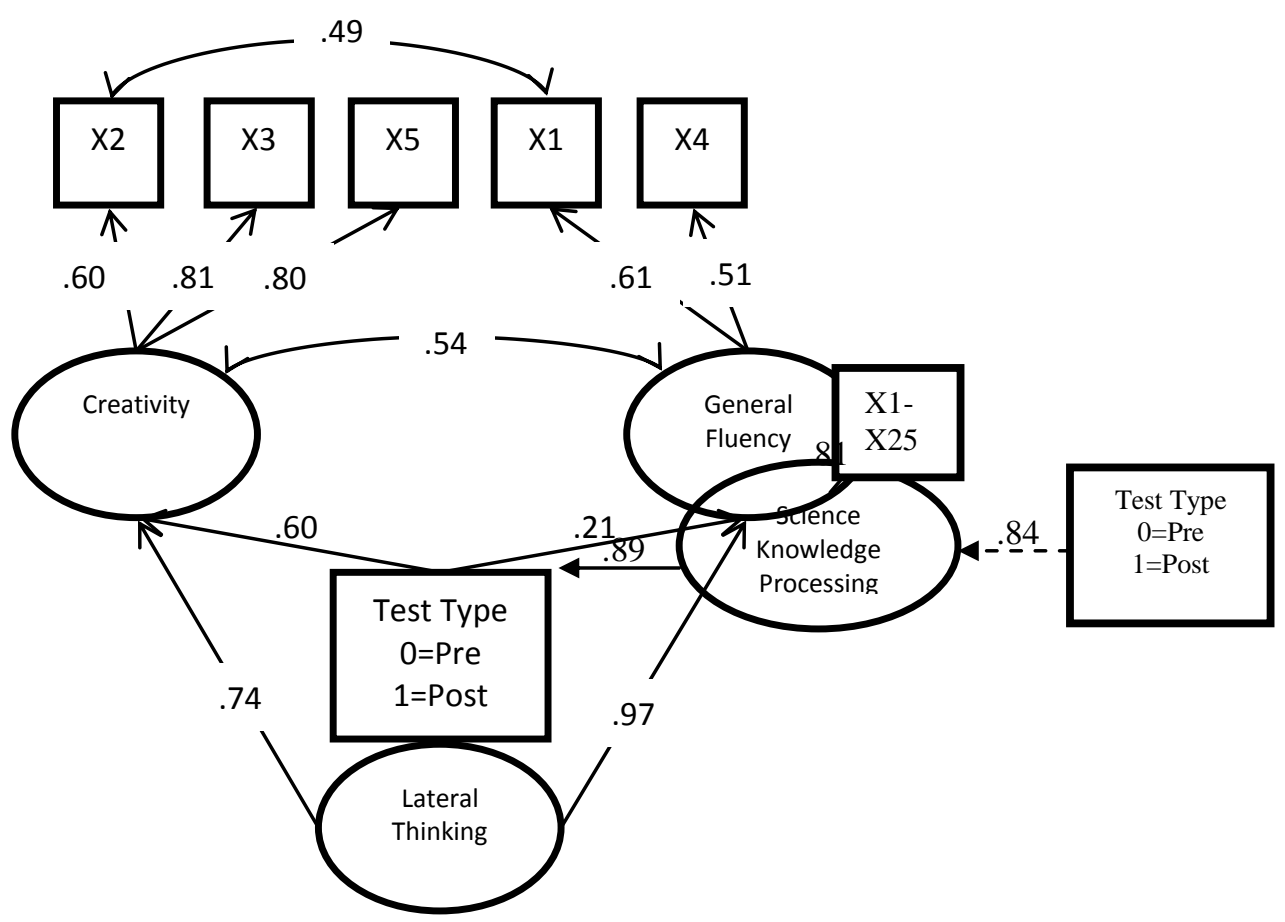

Figure 1. Confirmatory model of creativity, lateral thinking, and general fluency

The structural coefficient with the path from "TEST TYPE" to creativity (.60) and general fluency (.21) is statistically significant thus indicating that the two groups pretest and posttest differ on the latent constructs of creativity and general fluency. Given the group coding $0=$ pretest and $1=$ posttest the positive loading suggest that the posttest group resulted in higher scores by an amount of 10.62 points for creativity and 2.46 points for fluency. Due to the significant intercorrelation coefficient between creativity and general fluency, a second order latent trait (Lateral Thinking) is justified. After the addition of the lateral thinking mediator to the model no significant change in model fit was observed $\left(\Delta X^{2}(4)=0.24, p=0.12\right)$. The study authors also suggest the interface between science learning and creativity occurs through the mediation of lateral thinking as identified by the dotted line for clarity. 


\section{Discussion}

Answering Research Question 1, what is the relationship between creativity, general fluency, and lateral thinking? The model (figure 1) resulting from the current data is consistent with models of creativity as discussed in the literature with the addition of evidence of lateral thinking as an integrative cognitive system acting as a second order construct. This model outlines the relationships between the constructs. The addition of lateral thinking as a second order integrative cognitive system answers research question 2; what is the role of lateral thinking in relation to science learning? This model and the resulting evidence is suggestive of lateral thinking as an integrative system. In addition, the current theoretical model developed by the study authors accounts for the role of fluency as a cognitive covariate to creativity and lateral thinking as an integrator of science information processing related to both fluency and creativity. The cognitive architecture in lateral thinking fulfills the integrative need within the processing of science and other information data stream arising from information processing. This view arises with the understanding that creativity and fluency are the outward behavioral manifestations of the cognitive systems associated with the lateral thinking. The specific cognitive architecture of lateral thinking that supports integration is associated with the frontal lobe. While this area of the brain does not receive direct sensory input nor store long term memory it is responsible for the integration or processed information from other a disintegrative cognitive systems consisting of attributes as proposed by Lamb et. al., (2013 and 2014). Some examples of the attributes specifically suggested by authors are critical thinking, parity judgment, and retrieval. Other aspects of this cognitive architecture allow for the integration of information in temporal and spatial order within the data channel view of cognition.

Results of the TTCT post interventions suggest that the use and design of science based Serious Educational Games as part of a larger science curriculum initiative provides increases in creativity and more interestingly fluency answering Research Question 3, does the use of science based SEGs improve creativity behaviors as exhibited on the Torrance Test of Creative Thinking? These results are expected in this study when one considers lateral thinking as an integrative cognitive system. SEG design and play is inherently requires the integration and organization of information streams spatially and temporally (Drachen \& Canossa, 2011). Within this context, a mechanism of action for the gains seen within the study would reasonably be that through repeated stimulation of the lateral thinking cognitive sys- 
tems and attributes, the players are undergoing attributional retraining through game play and design. Attributional retraining will result in increased fluency as seen in this study. As a behavioral outcome, the increase in fluency (superimpositions of data streams) will result in increased attempts in a low failure with the accompanying affective states. These affective states and low impact environment provided by a virtual learning environment encourage increased persistence in superimposition (Lamb, et. al., 2013). The virtual environment will also increase the provision of superimpositions of knowledge constructs during the attempt to solve science-based tasks as the task can be presented as often as the student needs to stimulate superimposition attempts.

\section{Implications for Practitioners}

Proposed creativity support tools such as SEGs within the science classroom are meant to serve individuals as they grapple with ill-structured problems across curriculum disciplines. Convergence of the cross curriculum approach found in the intervention provides a mean to bridge the design processes to that of creativity and fluency with the processes of "doing science" via lateral thinking. This bridging action provides a means to target interventions and in turn has increased interest in creativity for members of the school community. The sets of design principles or patterns can be stimulated and developed as means to modify interact and engage in much of the learning process. As the creative composition in the form of the design and development of Serious Educational Games, progresses these results suggest that the way tools and representations are presented in the intervention can strongly effect lateral thinking and the promotion of creativity and fluency due to dissonance in superimposition. In this way, the use of attribution retaining via lateral thinking processes occurring during the design and development of the Serious Educational Games provides and explanatory mechanism for the shift in creativity from pretest to posttest.

Academic domains such as those associated with STEM learning receive considerable attention and funding, however, current models within the STEM classroom provide for a one-size fits all learning environment. While there is considerable effort put forward by practitioners to target interventions and instruction, it is sometimes difficult for the practitioner to identify, the role of affective traits and cognitive attributes impact on behaviors such as creativity and fluency. This lack of identification may be due to overdependence on grade-based data as there is often little else for the teacher to use to train behaviors associated with the manifestation of creativity and fluency. The use of creativity tools such as the design and de- 
velopment of SEGs appears to increase the ability of students to make leaps of intuition. This model offers a glimpse of the important role that factors such as fluency and creativity play in the design process and by extension the science learning process.

The role of fluency is much more difficult to explain. The inclusion of fluency seems to identify it as a means to aid in the development of the design process. Just as fluency in the language means, much more than knowing the structure and rules of language, fluency in science (design) helps the individual to state the importance of tools and aid in the development of new ways of thinking through superimpositions. This may result from the increase in the number of attempts to solve the problems resulting in novel approaches.

\section{Conclusion}

Seeking to promote interest in creative support tools such as those in use during the design of SEGs can provide disciplinary convergence through lateral thinking. More specifically these result agree with results found in other studies such as Yamamoto \& Nakakoji (2005), Chen et.al. (2007 ) and Spencer, Lucas \& Claxton (2012), which suggest that there are underlying behavioral manifestations of creativity and fluency that impacts the science and design process via lateral thinking. This result is expected, as the current model in this paper and other models of creativity and fluency within the academic forum have shown that creativity provides a means to develop novel outcomes and can lead to leaps of intuition. Training creativity and fluency via lateral thinking with targeted interventions at critical times may help to rebuild the current deficit in innovation.

\section{References}

Achieve, Inc. (2013). The Next Generation Science Standards. Retrieved from http://www.nextgenscience.org

Adams, R. S., Turns, J., \& Atman, C. (2003). Educating effective engineering designers: The role of reflective practice. Design Studies, 24, 275-294. doi.org/10.1016/S0142694X(02)00056-X

Almeida, L., Prieto, L., Ferrando, M., Oliveria, E., \& Ferrandiz, C. (2008). Torrance test of creative thinking: the question of its construct validity, Thinking Skills and Creativity, 3(1), 53-58. doi.org/10.1016/j.tsc.2008.03.003 
Amabile, T. M. (1983). The social psychology of creativity: A componential conceptualization. Journal of personality and social psychology, 45(2), 357. doi.org/10.1037/00223514.45.2.357

Andreasen, N. \& Ramchandran, K. (2012). Creativity in art and science: are there two cultures? Dialogues in Clinical Neuroscience, 14(1), 49-54.

Anwar, M., Rasool, S., \& Haq, R. (2012). A comparison of creative thinking abilities of high and low achievers secondary school students, International Interdisciplinary Journal of Education, 1(1), 1-6.

Arciniegas, D. B., Anderson, C. A., \& Filley, C. M. (Eds.). (2013). Behavioral neurology \& neuropsychiatry. New York, NY: Cambridge University Press.

Atkinson, A. P., \& Adolphs, R. (2011). The neuropsychology of face perception: beyond simple dissociations and functional selectivity. Philosophical Transactions of the Royal SocietyB: Biological Sciences, 366(1571), 1726-1738. doi.org/10.1098/rstb.2010.0349

Baillargeon, R., Li, J., Gertner, Y., \& Wu, D. (2011). How do infants reason about physical events? The Wiley-Blackwell handbook of childhood cognitive development, 2, 11-48.

Barrès, V., Simons III, A., \& Arbib, M. (2013). Synthetic event-related potentials: a computational bridge between neurolinguistic models and experiments. Neural Networks, 37, 66-92.

Benedek, M., Jauk, E., Fink, A., Koschutnig, K., Reishofer, G., Ebner, F., \& Neubauer, A. C. (2014). To create or to recall? Neural mechanisms underlying the generation of creative new ideas. NeuroImage, $88,125-133$. doi.org/10.1016/j.neuroimage.2013.11.021

Bond, C. E., Philo, C., \& Shipton, Z. K. (2011). When There isn't a Right Answer: Interpretation and reasoning, key skills for twenty-first century geoscience. International Journal of Science Education, 33(5), 629-652. doi.org/10.1080/09500691003660364

Boysen, S. T., \& Capaldi, E. J. (Eds.). (2014). The development of numerical competence: Animal and human models. London, England: Psychology Press Taylor \& Fancis Group.

Brockner, J., \& Wiesenfeld, B. M. (1996). An integrative framework for explaining reactions to decisions: interactive effects of outcomes and procedures. Psychological bulletin, 120(2), 189. doi.org/10.1037/0033-2909.120.2.189

Camazine, S. (Ed.). (2003). Self-organization in biological systems. Princeton, NJ: Princeton University Press.

Cattell, R. B. (1956). Validation and intensification of the sixteen personality factor questionnaire. Journal of Clinical Psychology, 112, 205-214. doi.org/10.1002/1097-4679 
Chen, M., Liou, Y., Wang, C., Fan, Y., \& Chi, Y. (2007). TeamSpirit: Design, implementation and evaluation of a web-based group decision support system, Decision Support Systems, 43(4), 1186-1202. doi.org/10.1016/j.dss.2005.07.008

Chow, C. (2012). Learning from our global competitors: A comparative analysis of science, technology, engineering and mathematics (STEM) education pipelines in the United States, Mainland China and Taiwan.World Economic Forum.

Christoff, K., Gordon, A., Smith, R., \& Vancouver, B. C. (2011). The role of spontaneous thought in human cognition. Neuroscience of Decision Making, 259-284.

Common Core Standards Initiative (2014). Common Core Standards. Retrieved from http://www.corestandards.org/

Crowder, J. A., Carbone, J. N., \& Friess, S. A. (2014). Cognitive Intelligence and the Brain: Synthesizing Human Brain Functions. In Artificial Cognition Architectures (pp. 2752). New York, NY: Springer. doi.org/10.1007/978-1-4614-8072-3_4

Crutchfield, R. (1962). Conformity and creative thinking. Contemporary approaches to creative thinking, New York New York: Atherton Press.

Deininger, G., Loudon, G., \& Norman, S. (2012). Modal preferences in creative problem solving, Cognitive processing, 13(1), 147-150. doi.org/10.1007/s10339-012-0479-3

Dietrich, A. (2003). Functional neuroanatomy of altered states of consciousness: the transient hypofrontality hypothesis. Consciousness and cognition, 12(2), 231-256. doi.org/10.1016/S1053-8100(02)00046-6

Dimitrov, D. (2012). Statistical methods for validation of assessment scale data in counseling and related fields, Alexandria, VA: American Counseling Association.

Drachen, A., \& Canossa, A. (2011). Evaluating motion: Spatial user behaviour in virtual environments. International Journal of Arts and Technology,4(3), 294-314. doi.org/10.1504/IJART.2011.041483

Duncan, J. (2013). The Structure of Cognition: Attentional Episodes in Mind and Brain. Neuron, 80(1), 35-50. doi.org/10.1016/j.neuron.2013.09.015

Ellamil, M., Dobson, C., Beeman, M., \& Christoff, K. (2012). Evaluative and generative modes of thought during the creative process. Neuroimage, 59(2), 1783-1794. doi.org/10.1016/j.neuroimage.2011.08.008

Goodchild, M. F., \& Janelle, D. G. (2010). Toward critical spatial thinking in the social sciences and humanities. GeoJournal, 75(1), 3-13. doi.org/10.1007/s10708-010-9340-3

Gotz, I. (1981). On defining creativity, The Journal of Aesthetics and Art Criticism, 39(3), 297-301. doi.org/10.2307/430164 
Gramann, K., Gwin, J. T., Ferris, D. P., Oie, K., Jung, T. P., Lin, C. T., \& Makeig, S. (2011). Cognition in action: imaging brain/body dynamics in mobile humans, Reviews in the Neurosciences, 22(6), 593-608. doi.org/10.1515/RNS.2011.047

Haigh, M. (2013). Fostering Creativity Through Science Education. Encyclopedia of Creativity, Invention, Innovation and Entrepreneurship, 744-748. New York, NY: Springer. doi.org/10.1007/978-1-4614-3858-8_365

Halpern, D. F. (1998). Teaching critical thinking for transfer across domains: Disposition, skills, structure training, and metacognitive monitoring. American Psychologist, 53(4), 449. doi.org/10.1037/0003-066X.53.4.449

Holliday, G. M., \& Lederman, N. G. (2013). Informal Science Educators’ Views about Nature of Scientific Knowledge. International Journal of Science Education, Part B, (aheadof-print), 1-24.

Hu, L. \& Bentler, P. (1999). Cutoff criteria for fit indexes in covariance structural analysis: Conventional criteria versus new alternatives. Structural Equation Modeling, 6, 1-55. doi.org/10.1080/10705519909540118

Kaufman, J., Plucker, J. \& Russell, C. (2012). Identifying and assessing creativity as a component of giftedness, Journal of Psychoedcuational Assessment, 30(1), 60-73. doi.org/10.1177/0734282911428196

Kurzban, R., Duckworth, A., Kable, J. W., \& Myers, J. (2013). Cost-benefit models as the next, best option for understanding subjective effort. Behavioral and Brain Sciences, 36(06), 707-726. doi.org/10.1017/S0140525X13001532

Lamb, R. L. (2013). The application of cognitive diagnostic approaches via neural network of analysis of serious educational games. Doctoral dissertation. George Mason University.

Lamb, R. (2014). Examination of allostasis and online laboratory simulations in a middle school science classroom. Computers in Human Behavior,39, 224-234. doi.org/10.1016/j.chb.2014.07.017

Lamb, R., \& Annetta, L. (2009). A pilot study of online simulations and problem based learning in a chemistry classroom. Journal of Virginia Science Educator, 3(2), 34-50.

Lamb, R., \& Annetta, L. (2012a). Influences of gender on computer simulation outcomes. Meridian, 13(1). doi: 10.1007/s10956-012-9417-5

Lamb R., and Annetta L. (2012b). The use of online modules and the effect on student outcomes in a high school chemistry class, Journal of Science Education and Technology, Online publication. doi: 10.1007/s10956-012-9417-5 
Lamb, R., Annetta, L. Meldrum, J., \& Vallett, D. (2011). Measuring science interest: Rasch validation of the science interest survey. International Journal of Science and Mathematics Education, 10(3), 643-668. doi.org/10.1007/s10763-011-9314-z

Lamb, R. L., Annetta, L., Vallett, D. B., \& Sadler, T. D. (2014). Cognitive Diagnostic Like Approaches Using Neural Network Analysis of Serious Educational Videogames. Computers \& Education. doi.org/10.1016/j.compedu.2013.08.008

Lamb, R. L., Vallett, D., \& Annetta, L. (2014). Development of a Short-Form Measure of Science and Technology Self-efficacy Using Rasch Analysis, Journal of Science Education and Technology, 1-17. doi.org/10.1007/s10956-014-9491-y

Lamb, R. L., Vallett, D. B., Akmal, T., Baldwin, K. (2014). A computational modeling of student cognitive processes in science education. Computers \& Education, 79, 116125. doi.org/10.1016/j.compedu.2014.07.014

Marsh, H. W., Morin, A. J., Parker, P. D., \& Kaur, G. (2013). Exploratory structural equation modeling: An integration of the best features of exploratory and confirmatory factor analysis. Annual Review of Clinical Psychology, (0). doi: 10.1146/annurev-clinpsy032813-153700. doi.org/10.1146/annurev-clinpsy-032813-153700

McComas, W. F. (2012). Darwin's error: using the story of pangenesis to illustrate aspects of nature of science in the classroom. The American Biology Teacher, 74(3), 151-156. doi.org/10.1525/abt.2012.74.3.5

Morcom, A. M., Bullmore, E. T., Huppert, F. A., Lennox, B., Praseedom, A., Linnington, H., \& Fletcher, P. C. (2010). Memory encoding and dopamine in the aging brain: a psychopharmacological neuroimaging study. Cerebral Cortex,20(3), 743-757. doi.org/10.1093/cercor/bhp139

Meyer, A. A., \& Lederman, N. G. (2013). Inventing creativity: An exploration of the pedagogy of ingenuity in science classrooms. School Science and Mathematics, 113(8), 400-409. doi.org/10.1111/ssm.12039

Myers, B. A., Hudson, S. E., \& Pausch, R. (2000). Past, present and future of user interface software tools. ACM Transactions on Computer Human Interaction, 7, 3-28. doi.org/10.1145/344949.344959

Myers, D. G. (1995). Psychology (4th Edition).New York: Worth Publishers Inc.

Onarheim, B., \& Friis-Olivarius, M. (2013). Applying the neuroscience of creativity to creativity training. Frontiers in Human Neuroscience, 7, 656. doi.org/10.3389/fnhum.2013.00656 
Raykov, T. (2004). Estimation of maximal reliability: A note on a covariance structure modeling approach. British Journal of Mathematical and Statistical Psychology, 57, 21-27. doi.org/10.1348/000711004849295

Ray, K., \& Smith, M. (2010). The kindergarten child: What teachers and administrators need to know to promote academic success in all children, Early Childhood Education Journal, 38(1), 5-18. doi.org/10.1007/s10643-010-0383-3

Resnick, M., Berg, R., \& Eisenberg, M. (2000). Beyond black boxes: Bringing transparency and aesthetics back to scientific investigation. Journal of the Learning Sciences, 9, 7 30.

Roy, M., Shohamy, D., \& Wager, T. D. (2012). Ventromedial prefrontal-subcortical systems and the generation of affective meaning. Trends in cognitive sciences, 16(3), 147-156.

Ruo, B. Baker, D. Thompson, J. Murray, P., Huber, G. \& Sudano, J. (2008). Patients with worse mental health report more physical limitations after adjustments for physical performance, $\quad$ Psychosomatic $\quad$ Medicine, 70, 417-421. doi.org/10.1097/PSY.0b013e31816f858d

Shneiderman,B., et.al. (2008). Creativity support tools: Repost from a U.S. National Science Foundation, International Journal of Human-Computer Interaction, 20(2), 61-77. doi.org/10.1207/s15327590ijhc2002_1

Simmons, B. (2010). Clinical reasoning: concept analysis. Journal of Advanced Nursing, 66(5), 1151-1158. doi.org/10.1111/j.1365-2648.2010.05262.x

Sawyer, R. K. (2011). Explaining creativity: The science of human innovation. New York, NY: Oxford University Press.

Spencer, E. Lucas, B. \& Claxton, G. (2012). Progression in creativity-developing new forms of assessment: A literature review, Creativity, Culture and Education.

Steiger, J. (1990). Some additional thoughts on components, factors and factor indeterminacy, Multivariate Behavioral Research, 25, 41-45. doi.org/10.1207/s15327906mbr2501_4

Surkova, I. (2012). Towards a creativity framework, Society and Economy, 34(1), 115-138. doi.org/10.1556/SocEc.2011.0013

Thorstuon, L. (1952). Creative talent. Applications of Psychology, New York, NY: Harper \& Row.

Torrance, E. (1970). Achieving socialization with sacrificing creativity. Journal of Creative Behavior, 4, 183-189. doi.org/10.1002/j.2162-6057.1970.tb00858.x 
Tseng, S. W. W., \& Lin, C. H. (2012). A Study on the Application of Design Thinking Strategy to Form Generation System. Advanced Materials Research, 502, 376-380. doi.org/10.4028/www.scientific.net/AMR.502.376

Urhahne, D., Kremer, K., \& Mayer, J. (2011). Conceptions of the nature of science-are they general or context specific? International Journal of Science and Mathematics Education, 9(3), 707-730. doi.org/10.1007/s10763-010-9233-4

Vartanian, O., Bristol, A. S., \& Kaufman, J. C. (Eds.). (2013). Neuroscience of Creativity. Cambridge, MA: MIT Press. doi.org/10.7551/mitpress/9780262019583.001.0001

Wilson, K., Vyakarnam,S., Volkmann, C., Mariotti, S. \& Rabuzzi, D. (2009). Educating the next wave of entrepreneurs unlocking entrepreneurial capabilities to meet the global challenges of the $21^{\text {st }}$ century, World Economic Forum: A report of the Global Education Initiative.

Yamamoto, Y., \&Nakakoji, K. (2005). Interaction design of tools for fostering creativity in the early stages of information design. International Journal of Human-Computer Studies, 63, 513-535. doi.org/10.1016/j.ijhcs.2005.04.023

Zangeneh, M., Omid, M., \& Akram, A. (2012). A comparative study between parametric and artificial neural networks approaches for economical assessment of potato production in Iran. Spanish Journal of Agricultural Research,9(3), 661-671. doi.org/10.5424/sjar/20110903-371-10 